\title{
NATURE CONSERVATION AS A RESOURCE FOR TOURISM
}

\section{T C OWEN}

\author{
Director \\ South African Tourist Corporation \\ Private Bag X164 \\ Pretoria \\ 0001
}

The spectacular development in air technology during and since the Second World War, and a parallel economic growth, have been responsible for a tremendous increase in international tourist statistics, making tourism the world's largest industry. For the sake of clear international definition, a tourist is regarded as a person who visits a country other than his country of normal residence, for any reason other than being gainfully employed within the country he visits. During 1975 such tourist arrivals numbered 213 million, and the receipts from international tourism amounted to US $\$ 32000$ million. Domestic tourism also plays an important rôle in most countries. It is the rule rather than the exception that the local tourist creates the demand for the development of amenities, which can then cater for the tourist from abroad.

Tourism today is highly organised. The private sector provides hotels and transport. Governments, however, have a major responsibility in financing communication links, including air and surface transport, and the building of roads. Governments also play a leading part in the organisation and planning of tourism, which could and should include setting aside areas for nature conservation.

The South African Tourist Corporation (Satour), responsible for the promotion of tourism to the Republic of South Africa (RSA) from abroad for the purpose of earning foreign exchange, is a statutory body established in 1947. In its international marketing operation Satotar is supported and assisted by the South African Airways and its pool partners, other air and shipping lines, travel wholesalers, tour operators, approximately 20000 travel agents overseas, motoring clubs and South African missions abroad. Satour relies on the co-operation of the Department of Tourism and its National Tourist Bureaux, other State Departments, the South African Railways, provincial and local authorities, the Hotel Board, publicity associations, hoteliers, ground operators and - last but certainly not least - the National Parks Board of Trustees of the Republic of South Africa. 
The RSA as a tourism product has many components. To list just a few of the main components, I would immediately think of our country's scenery, climate, mineral wealth and its national parks as they are so well described in Satour's tourist literature:

Geographically, we have been endowed in this small tip of Africa with many climates. The northernmost reaches of the Republic lie just within the Tropic of Capricorn; in the south, the city of Cape Town faces out on to the Atlantic Ocean, which sweeps to meet the Indian Ocean at Cape Agulhas, in a wild union of force and beauty. If one could orbit the earth in a space ship and look down on southern Africa, it would seem that at some moment in the heat of creation the entire continent tipped forward and the hot wrinkled skin of the land slid down towards the sea, but before it could disappear hissing and bubbling under the waves, the continent bobbed up, righting itself, and there at the edge the great mass remained solidified into towering escarpments, fold upon fold, forming an enormous mountain barrier between the interior and the two oceans.

On the north-west coast the mountains are scoured by the spuming fury of the Atlantic which carries in its restless fists, the cold Benguela Current washing up from the Antarctic wastes. It brings no gift of rain to that infamous stretch of land between the mountains and the sea known as the Skeleton Coast. Beyond the windswept barrier, stretching inland to the north and east, are the arid lands of Namaqualand and the Karoo - dry land that merges with the Kalahari Desert, huge, silent and curiously beautiful.

Prevailing winds bring about a fine mediterranean climate at the South West Cape, and from there around the coast the scene mellows. Mountains are green-clad with natural forests.

Inland, protected by the mountains, the land rises to great plateaus. The Highveld soars to $2000 \mathrm{~m}$, where winter nights are frosty and the days bright with sun. To the east, by way of a great escarpment, the land plunges down to the warm Lowveld area, thick with bush, and habitat of the greatest variety of African animals.

I would point out that there is probably not a region in the world where the variety of mineral wealth is so vast. The RSA has a soil so varied in mineral content and a terrain so varied in physical characteristics and climate, that it has given rise to an overwhelming variety of plants. Of the world's 300 or so families of flowering plants, 190 are represented in the RSA - 18000 species in all. The plants nurture a wide variety of herbivores - grazing for the hippo, white rhino, zebra and buffalo, treetop browsing for the giraffe, leaves for the kudu, shrubs for the eland, bark for the porcupine, berries for monkeys, baboons and birds, branches for the elephant, and thorn trees for the black rhino. These in turn provide food for a spectacular variety of carnivores jackals of many kinds, foxes, hyeanas, seven different felines, including the lion and the spotted cats.

In recent years, as it becomes obvious that people are no longer 
content to travel the world viewing cities and the works of man, the RSA has endeavoured to find a happy compromise between continuing the development of one of the world's materially very wealthy regions, and fulfilling her obligations as custodian to a unique concentration of wildlife by the establishment and subsequent development of the National Park Board of Trustees.

To be really attractive to the international tourist, a country does not only need amenities and facilities such as sophisticated hotels and transport, but must have features which are unique unto itself. Europe, where mediaeval architecture and other antiquities abound, is at present our main source of tourism. The European tourist who is surrounded and feels stifled perhaps by people and buildings, yearns for wide open spaces, a sunny climate, a smogless environment, and, most of all, responds to the "return to nature" call. A strong motivation for travel would be the need for man's temporary flight from artificiality towards unsullied nature. To find peace of mind, how could he spend his savings and leisure time better than in a nature conservation area?

The RSA has such a variety of tourist attractions that Satour in its marketing concentrates on the all-incorporating advertising slogan "A World Tour in One Country". Of all the attractions, the nature and game reserves surpass them all. A recent survey conducted by Satour in 10 countries established that $23 \%$ of the total sample chose to visit the RSA's game reserves; the only higher percentage being that of overseas visitors wanting to visit friends and relatives. They would, once here, also wish to have the opportunity of experiencing our national parks. The National Parks Board of Trustees, through its avowed policy of conservation, created a tourist product which Satour, as a tourist marketing organisation, exploits to its fullest advantage.

In 1657, on the 26th October, Jan van Riebeeck as Commander of the Cape of Good Hope, made an entry in his journal. Part of it reads: "The Commander today went to inspect a forest ... the free carpenter, Leendert Cornelissen of Zevenhuisjen, wished to have the sole right to obtain timber from it, in such a way that the forest would suffer no damage, but would be improved ...". These words inspired one of Satour's highly successful advertising campaigns, embodied in the slogan "Conservation is a 300-Year-Old-Word in the RSA".

Satour's marketing overseas has been notably successful. The total visitor arrival figure for 1975 was 730368 , an increase of $20 \%$ on the figure for 1974 . Tourists from our neighbouring territories comprise $45 \%$ of total arrivals, namely 327380 , which represents an increase of $12 \%$ on that of 1974 .

Most countries with large tourist intakes rely heavily on overborder marketing areas for their main supply of tourists. The RSA does not have that potential nearby, but has to look towards overseas countries such as the United Kingdom, United States of America (USA) and Germany for tourists. In view of this, it is encouraging to note that 10 
years ago a meagre $27 \%$ of our visitor arrivals came from overseas, whereas in 1975 the numbers of overseas visitors increased to $55 \%$ of all tourist arrivals. Main sources of tourism from overseas were: the United Kingdom 140324 , (this is an increase of $34 \%$ on the 1974 figure). The USA with 48712 was on $14 \%$, Germany 41506 (+26\%), Australia $20654(+15 \%)$ and Holland $18238(+27 \%)$. The average length of stay for these tourists was 19 days, and the estimated earnings of R274 million in foreign exchange during 1975 was an all time record.

Although it will require all our marketing skills this year to improve on the record 1975 figures - due in part to a slight and, we believe, temporary hesitancy about travelling to the RSA after the unrest in black townships received such wide coverage abroad - the overall picture is good. Satour has set itself the marketing target of a million visitors by 1980 and is confident this target will be reached a year or two ahead of schedule.

It has, however, been pointed out that tourism, with the multitudes that it brings with it, harbours the seeds of destruction. Visitors in ever growing numbers flock to the national parks in the USA - some 50 million in 1955, more than 110 million in 1965 and according to the latest estimate, more than 200 million in 1976. During July 1976, visitors to the Yellowstone National Park were caught in traffic jams. It is reported that similar scenes are being played out every day this season in America's 285 national parks, recreation areas and historic sites. By the end of May 1976, for example, Yellowstone had $70 \%$ more visitors than in the first five months of last year. By the end of June 1976, the nearby Grand Teton National Park reported an increase of $38 \%$. Yosemite National Park in California registered a $63 \%$ increase through May 1976. The National Parks and Conservation Association has published a stark report detailing manpower deficiencies and deteriorating conditions throughout the system.

Although we are many years away from these staggering numbers and acute problems, it is emphatically not too early to support the Chief Director of National Parks in the RSA in his call for the conservation of many natural wonders, ecosystems and plant and animal species that still exist without protection, on a national level. New conservation areas will not only serve the cause of wild life protection but will spread the flow of tourism in the future. Dr Knobel said in 1972 that our generation is the last one to have the opportunity of setting aside space for conservation; no other country on this earth has the existing possibilities and versatility as the RSA has for the establishment of nature areas, and thus enhancing the diversity of our tourist product. The demonstrable fact that it is possible to use agricultural land more gainfully for touristic purposes should not be forgotten.

It was estimated by the Department of Agricultural Economics and Marketing that the annual agricultural income of the Addo Elephant National Park would have been R15 000 while its tourist income was 
R45 000. Similarly the agricultural income of the Mountain Zebra National Park and the Augrabies Falls National Park would have been R11 000 and R2 500 respectively whereas from tourism it was actually R18 000 and R28 200. In the Kruger National Park the annual agricultural income was estimated at approximately R3 million compared to an amount of nearly R6 million derived from tourism. It is apparent therefore that tourism does have its blessings, even in the field of nature conservation; moreover the valuable influx of foreign exchange draws the government's attention to the value of nature conservation, not merely for nature's sake alone, but also for the sake of the country's economics as well as its foreign image.

One cannot deny the interdependence of nature conservation and tourism. To carry out nature conservation money is needed, and this tourism can supply. The same tourists who need and seek wild life, are the ones who provide the necessary funds for its upkeep and expansion. A Zulu who had completed a course at the Wilderness Leadership school aptly summed up this interdependence with the words: "We were very impressed. We were told that the game reserves the Zulu is about to inherit don't belong to us, they belong to the world. But if they belong to the world, then let the world pay for their upkeep, because we can't afford to". These wise words bring two things to our attention: that our heritage of abundant nature is to be shared with the rest of the world, and also, that the rest of the world, in the form of tourism, is the medium by which this can be financed. Let us, in this age in which so many values seem to be in a precarious balance, appreciate the work done by our nature conservationists for, as Carl Linnaeus wrote 200 years ago: "There is no place on earth with such a variety of rare plants, animals, insects and other marvels of nature as Africa".

Even with our open spaces, sunny climate and different cultures, we find ourselves on a very competitive basis with other countries of the world. However, in the sphere of wildlife parks, the RSA is rated among the best in the world. Other competing countries, which also have similar potentials, seem to be losing out on their tourist business because of malpractices contrary to nature conservation in their parks, and because they do not have the conservation-orientated policy which our National Parks Board of Trustees so strictly applies.

We must remember that all natural resources can be exhausted, but nature, which has been conserved, has no limits; it can only grow and grow into abundance. The more the world expands industrially, the more our nature conserving projects will come to be valued and sought after so that it is certain that the next 50 years of nature conservation in the RSA will be more prosperous than the 50 fruitful years that have passed. 